Correction

\title{
Correction: Fararjeh, A-F S., et al. ZBTB46, SPDEF, ETV6 Novel Potential Biomarkers and Therapeutic Targets in Castration Resistance Prostate Cancer. Int. J. Mol. Sci. 2019, 20, 2802
}

\author{
Abdul-Fattah Salah Fararjeh ${ }^{1}$ and Yen-Nien Liu ${ }^{2,3, *(\mathbb{D})}$ \\ 1 Department of Medical Laboratory Sciences, Faculty of Science, Al-Balqa Applied University, \\ Al-Salt 19117, Jordan; Fararjehas@bau.edu.jo \\ 2 Ph.D. Program for Cancer Molecular Biology and Drug Discovery, College of Medical Science and \\ Technology, Taipei Medical University, Taipei 11031, Taiwan \\ 3 Graduate Institute of Cancer Biology and Drug Discovery, College of Medical Science and Technology, \\ Taipei Medical University, Taipei 11031, Taiwan \\ * Correspondence: liuy@tmu.edu.tw; Tel.: +886-2-2697-2035 (ext. 113); Fax: +886-2-2697-2133
}

The authors wish to make the following correction to this paper [1]: PSA, which was described as being initiated in "1979", was actually initiated in "1970".

The authors would like to apologize for any inconvenience caused to the readers by this change.

\section{Reference}

1. Fararjeh, A.-F.S.; Liu, Y.N. ZBTB46, SPDEF, ETV6 novel potential biomarkers and therapeutic targets in castration resistance prostate cancer. Int. J. Mol. Sci. 2019, 20, 2802. [CrossRef] [PubMed]

(C) 2020 by the authors. Licensee MDPI, Basel, Switzerland. This article is an open access article distributed under the terms and conditions of the Creative Commons Attribution (CC BY) license (http://creativecommons.org/licenses/by/4.0/). 